\title{
Laparoscopic hepatectomy for hepatocellular carcinoma: short- and long-term outcomes with blood loss
}

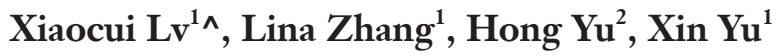 \\ ${ }^{1}$ Department of Anesthesia, Sir Run Run Shaw Hospital, Zhejiang University School of Medicine, Hangzhou, China; ${ }^{2}$ Department of General \\ Surgery, Sir Run Run Shaw Hospital, Zhejiang University School of Medicine, Hangzhou, China \\ Contributions: (I) Conception and design: H Yu, X Yu; (II) Administrative support: H Yu, X Yu; (III) Provision of study materials or patients: H Yu, X \\ Yu; (IV) Collection and assembly of data: X Lv, L Zhang; (V) Data analysis and interpretation: X Lv; (VI) Manuscript writing: All authors; (VII) Final \\ approval of manuscript: All authors. \\ Correspondence to: Xin Yu. Department of Anesthesia, Sir Run Run Shaw Hospital, Zhejiang University School of Medicine, No. 3 Qingchun East \\ Road, Hangzhou, China. Email: xinxin_yu@zju.edu.cn; Hong Yu. Department of General Surgery, Sir Run Run Shaw Hospital, Zhejiang University \\ School of Medicine, No. 3 Qingchun East Road, Hangzhou, China. Email: blueyu000@zju.edu.cn.
}

Background: Laparoscopic hepatectomy (LH) for treating hepatocellular carcinoma (HCC) is a complex procedure. Compared to open hepatectomy $(\mathrm{OH}), \mathrm{LH}$ offers certain advantages such as faster recovery, smaller incisions, and shorter hospital stay, but bleeding during LH remains a significant concern. Currently, the impacts of blood loss on the short- and long-term outcomes of patients undergoing LH are poorly understood. This retrospective study analyzes the impacts of blood loss on the prognosis of LH in HCC patients.

Methods: Between 2001 and 2019, 192 patients underwent LH for HCC at a single high-volume center. These patients were divided into two groups according to intraoperative blood loss (IBL) (Group A: $\leq 250 \mathrm{~mL}$; Group B: >250 mL). The patient characteristics assessed included age, gender, cirrhosis, hepatitis B virus (HBV) infection, Child-Pugh class, number of tumors, tumor size, vascular invasion, and diabetes mellitus. The perioperative and postoperative factors compared included operative time, blood loss, type of resection, blood transfusion, general complications, surgical complications, hospital mortality, and postoperative hospital stay.

Results: Factors associated with IBL in our multivariate analysis included the type of resection $(\mathrm{P}<0.01)$ and operative time $(\mathrm{P}<0.01)$. IBL, tumor size and number of tumors were independent predictors of a patient's overall survival (OS) and recurrence-free survival (RFS). Through our subgroup multivariate analysis, we found that IBL was the only significant factor associated with RFS $(\mathrm{P}<0.02)$. There was also a noted IBL "dose effect", as patients with IBL $>1,000 \mathrm{~mL}$ had a worse median OS (24 months) and median RFS (6 months), while patients with IBL 250-1,000 mL had a median OS of 36 months and RFS of 12 months, and patients with IBL $\leq 250 \mathrm{~mL}$ had a median OS of 36 months and RFS of 24 months.

Conclusions: We found that the extent of IBL during LH was related to tumor size, operative time, and surgery type. Increased IBL during LH was also an independent prognostic factor for tumor recurrence. Furthermore, a dose-response relationship between increased IBL and decreased RFS and OS was evident.

Keywords: Laparoscopic hepatectomy (LH); hepatocellular carcinoma (HCC); intraoperative blood loss (IBL); retrospective study; postoperative outcomes

Submitted Mar 15, 2021. Accepted for publication Aug 23, 2021.

doi: $10.21037 /$ tcr-21-463

View this article at: https://dx.doi.org/10.21037/tcr-21-463

$\wedge$ ORCID: 0000-0001-9252-532X. 


\section{Introduction}

In 2019, more than half of the world's liver cancer (LC) cases occurred in China. $80 \%$ of these cases were found to be at intermediate and advanced stages because of the high prevalence of hepatitis $\mathrm{B}$ virus (HBV) infection $(1,2)$. Surgical resection is still an effective treatment for advanced $\mathrm{LC}$; however, laparoscopic hepatectomy (LH) is becoming a common procedure in treating hepatocellular carcinoma (HCC). This is due to the widespread dissemination of laparoscopic technology (3) since the First International Consensus Conference on Laparoscopic Liver Resection in 2008 (4).

However, serious postoperative complications such as poor liver function combined with major surgical trauma are still prevalent among patients. Risk factors for complications related to open hepatectomy $(\mathrm{OH})$ include blood loss (5-9) type of resection (10), presence of comorbidity, HBV infection, cirrhosis (11), serum albumin levels (6), ChildPugh class, blood transfusion (12), anesthesia, and operative time (7). Previous studies have reported that intraoperative blood loss (IBL) can significantly affect the complication rate of laparoscopic LC surgery $(5,8)$. Compared to $\mathrm{OH}, \mathrm{LH}$ is more effective in terms of its impact on hospital stay, blood loss, and the complication rate (13-15). In colorectal cancer (16) and endometrial cancer (17) surgery, laparoscopic surgery also has the advantage of reducing blood loss. However, the laparoscopic surgical approach is more challenging; thus, few studies have elaborated on the independent impact it has on blood loss and the short- (8) and long-term outcomes of patients undergoing $\mathrm{LH}$ for HCC.

For this reason, our study analyzed 192 HCC patients who underwent $\mathrm{LH}$ to assess the impacts $\mathrm{LH}$ has on blood loss and short- and long-term outcomes. The findings of this study can be used to encourage surgeons to reduce the amount of bleeding during LH and enable surgeons and anesthesiologists to rationally use blood products based on the amount of IBL, thereby preventing patients from unfavorable prognostic risk factors during and after surgery.

We present the following article in accordance with the STROBE reporting checklist (available at https://dx.doi. org/10.21037/tcr-21-463).

\section{Methods}

\section{Study group}

The data of consecutive patients who underwent LH for
HCC from 2001 to 2019 at the Sir Run Run Shaw Hospital in Hangzhou, China, were retrieved retrospectively. Follow-up data were obtained from our material database and through direct contact via phone with patients and their families. There were 203 patients diagnosed with HCC and who underwent LH. However, we were unable to follow up with 9 of these patients due to incorrect contact information. This left a total of 192 HCC patients for our study. Table 1 displays the baseline characteristics of these remaining patients, while Table 2 lists the patients' surgical characteristics and surgical outcomes. Based on previously published reports on $\mathrm{OH}(8,18,19)$, the median IBL of HCC patients who underwent LH was 250 (range: 5-5,000) $\mathrm{mL}$.

For this reason, we divided the patients in our study into two groups: the first was for those with an IBL less than $250 \mathrm{~mL}$ (Group A: n=97), and the second was for those with an IBL of more than $250 \mathrm{~mL}$ (Group B: n=95). These two groups were then compared in terms of tumor characteristics, type of surgery, and prognosis. To better verify the impact of high levels of blood loss, we analyzed the correlation between different levels of blood loss and a patient's overall survival (OS) and recurrence-free survival (RFS).

The patient characteristics assessed included age, gender, cirrhosis, HBV infection, Child-Pugh class, number of tumors, tumor size, vascular invasion, and diabetes mellitus (Table 1). Perioperative and postoperative factors were compared, including the operative time, blood loss, type of resection, blood transfusion, general complications, surgical complications, hospital mortality, and postoperative hospital stay (Table 2).

\section{Surgical procedures}

The same experienced surgical team performed all operations, and all patients underwent multidisciplinary consultations with surgeons, radiologists, sonographers, anesthesiologists, nutritionists, and rehabilitation professionals before the operation.

Inflow and outflow control before segmentectomy and hemihepatectomy was routinely performed by Pringle maneuver, and the majority of resections were also performed with an intermittent Pringle maneuver. IBL was calculated by using the overall intraoperative volume collected with suction after the subtraction of the lavage volume and the gauze volume, which were weighed to calculate the bleeding volume. 
Table 1 Clinicopathologic variables

\begin{tabular}{|c|c|}
\hline Variables & $\mathrm{N}[\%]$ \\
\hline \multicolumn{2}{|l|}{ Age (years) ${ }^{\star}$} \\
\hline$\geq 60$ & $91[47]$ \\
\hline$<60$ & $101[53]$ \\
\hline \multicolumn{2}{|l|}{ Gender } \\
\hline Female & 48 [25] \\
\hline Male & $144[75]$ \\
\hline \multicolumn{2}{|l|}{ Child-Pugh } \\
\hline Class A & 169 [88] \\
\hline Class B & $21[12]$ \\
\hline \multicolumn{2}{|l|}{ Cirrhosis } \\
\hline Yes & 76 [40] \\
\hline No & $114[60]$ \\
\hline \multicolumn{2}{|l|}{ HBV infection } \\
\hline Yes & $109[57]$ \\
\hline No & 82 [43] \\
\hline \multicolumn{2}{|l|}{ No. of tumors } \\
\hline Multiple & 34 [18] \\
\hline Solitary & 157 [82] \\
\hline \multicolumn{2}{|l|}{ Tumors size (cm) } \\
\hline$\leq 3$ & $100[52]$ \\
\hline$>3$ & $91[48]$ \\
\hline \multicolumn{2}{|c|}{ Vascular invasion } \\
\hline Present & $7[4]$ \\
\hline Absent & $155[96]$ \\
\hline \multicolumn{2}{|l|}{ Diabetes mellitus } \\
\hline Yes & $18[9]$ \\
\hline No & 174 [91] \\
\hline \multicolumn{2}{|c|}{ Operative time (min) } \\
\hline$\geq 166$ & 72 [38] \\
\hline$<166$ & $120[62]$ \\
\hline \multicolumn{2}{|l|}{$\mathrm{IBL}(\mathrm{mL})$} \\
\hline$\leq 250$ & $97[51]$ \\
\hline$>250,<500$ & 95 [49] \\
\hline$\geq 500,<1,000$ & $60[31]$ \\
\hline$\geq 1,000$ & 25 [13] \\
\hline
\end{tabular}

Table 1 (continued)
Table 1 (continued)

\begin{tabular}{lc}
\hline Variables & $\mathrm{N}[\%]$ \\
\hline Blood transfusion & \\
Yes & $40[22]$ \\
No & $142[78]$ \\
\hline
\end{tabular}

*, median age: 58 (range: $20-86$ ) years. HBV, hepatitis B virus; IBL, intraoperative blood loss.

\section{Definition of complications}

Postoperative complications were defined and classified according to the modified Clavien-Dindo classification (20).

\section{Statistical analysis}

Quantitative variables are expressed as mean \pm standard deviation, and qualitative variables are expressed as frequencies (percentages). A Student $t$-test or MannWhitney $\mathrm{U}$ test was used for intergroup comparisons of quantitative variables when appropriate, whereas a Chisquare test or Fisher's exact test was used to compare categorical data. The OS and RFS were calculated by using the Kaplan-Meier method. The log-rank test compared differences between the groups of patients. All $\mathrm{P}$ values were two-sided, and a $\mathrm{P}$ value less than 0.05 was considered statistically significant.

Moreover, a Cox proportional hazards model was used for multivariate analysis to identify independent prognostic factors. Only potential predictive factors through a univariate analysis $(\mathrm{P}<0.05)$ were taken into the Cox model. The hazard ratio (HR) and $95 \%$ confidence interval (CI) were used to estimate the role of each independent prognostic factor. All statistical analyses were performed with SPSS version 23.0 software (IBM Corporation, Armonk, NY, USA).

The study was conducted in accordance with the Declaration of Helsinki (as revised in 2013). The study was approved by Institutional Ethics Board of Sir Run Run Shaw Hospital of Zhejiang University (No. 20190821-6) and individual consent for this retrospective analysis was waived.

\section{Results}

\section{Clinical characteristics of patients}

The clinical characteristics of the 192 HCC patients 
Table 2 Surgical characteristics and surgical outcomes compared to two groups

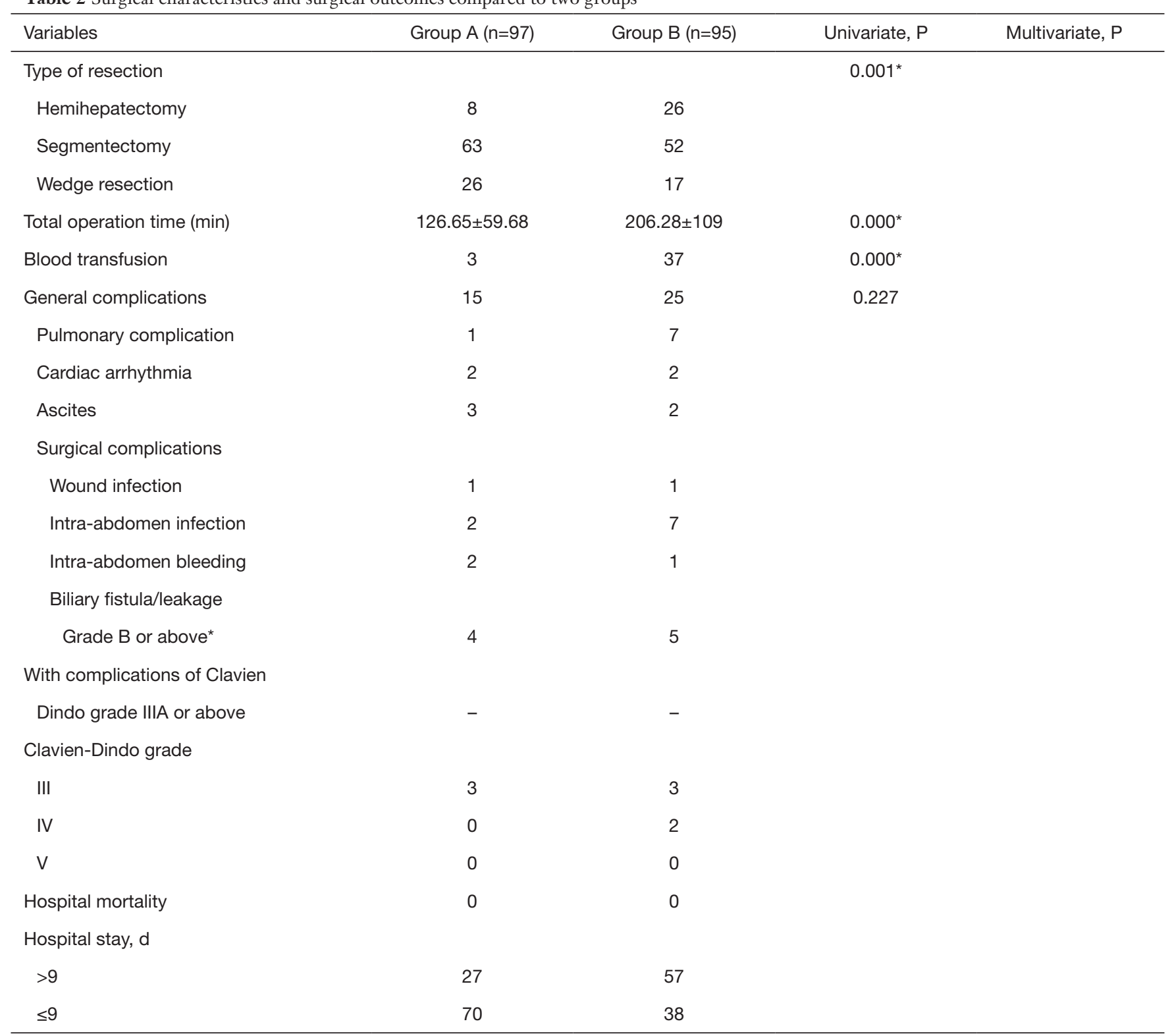

*, $\mathrm{P}<0.05$ is statistically significant.

are summarized in Table 1. There were 144 males and 48 females, with a median age of 58 (range: $20-86$ ) years. The median IBL was 250 (range: 5-5,000) mL. Fiftyseven percent of the patients carried HBV, while $57 \%$ also had cirrhosis, though only $12 \%$ of them were ranked class B by a Child-Pugh score. Median preoperative serum levels included 11.88 (range: $1-107,583$ ) $\mathrm{ng} / \mathrm{mL}$ of alphafetoprotein (AFP), 31 (range: 12-515) U/L of aspartate aminotransferase (AST), 29 (range: 3-449) U/L of alanine aminotransferase (ALT), while total bilirubin was 14.4 (range: $2-107) \mu \mathrm{mol} / \mathrm{L}$, and albumin was 40.2 (range: $5-54) \mathrm{g} / \mathrm{L}$. Tumor size varied from 1.0 to $12.0 \mathrm{~cm}$ (median: $3.0 \mathrm{~cm}$ ), and only $4 \%$ of the patients had a vascular invasion. The vast majority (84\%) of patients had a single tumor. The median operative time was 142.5 (range: $40-800$ ) min, and the blood transfusion rate was only $20 \%$. The median OS 
was 36 (range: $0-216$ ) months.

\section{Postoperative complications}

Complications were assessed following surgery and included specific surgery-related morbidity (bile leak, liver failure, and ascites) and general postoperative complications (respiratory complications, cardiac events, gastrointestinal complications, intra-abdominal infection, and neurologic events). The surgical characteristics and surgical outcomes of the two groups are shown in Table 2. The morbidity rate and severe complications of the two groups did not differ significantly.

\section{Risk factors for increased IBL during LH for HCC}

Only $20 \%$ of the 192 patients analyzed required a blood transfusion despite $32 \%$ having IBL greater than $500 \mathrm{~mL}$ and $13.5 \%$ having IBL greater than $1,000 \mathrm{~mL}$. The median IBL was 250 (range: 5-5,000) mL. In Table 3, the pathological features of the patients who had less than $250 \mathrm{~mL}$ of IBL are compared to the patients who had more than $250 \mathrm{~mL}$. We determined that tumor size, type of hepatectomy, and operative time had a significant association with a high level of blood loss through our univariate analysis. However, our multivariate analyses showed that only the type of hepatectomy and operative time contributed to a higher level of bleeding.

\section{Using IBL to predict survival after $L H$}

The mean and median OS of patients after LH were 39 and 36 months, respectively, while the mean and median RFS after LH were 24.5 and 24 months. The 3 - and 5-year OS rates were $53.1 \%$ and $24.5 \%$, respectively, while the 3 and 5 -year RFS rates were $38 \%$ and $16.7 \%$, respectively (Figure 1). To determine which pathological features were associated with OS after LH, we used the Kaplan-Meier analysis method. Some of the more significant risk factors determined through our univariate and multivariate analysis included tumor size $>3 \mathrm{~cm}$, number of tumors $>1$, and IBL $>250 \mathrm{~mL}$ (Figure 2). The odds ratio (OR) of these factors were 2.3 [95\% CI: (1.4-3.8), $\mathrm{P}<0.01$ ] 0.5 [95\% CI: $(0.3-0.8), \mathrm{P}<0.01$ ], and 0.5 [95\% CI: $(0.3-0.9), \mathrm{P}<0.02$ ], respectively (Table 4).

\section{Predictors of recurrence after $\mathrm{LH}$}

The general median recurrence time was 24 months and was significantly associated with IBL (Figure 2). Tumor size $>3 \mathrm{~cm}$, number of tumors $>1$, and IBL $>250 \mathrm{~mL}$ were significant predictors of HCC recurrence in our multivariate analysis (Table 5). The OR for these factors were $2.2[95 \%$ CI: (1.3-3.7), $\mathrm{P}<0.01], 0.4$ [95\% CI: (0.23-0.8), $\mathrm{P}<0.02$ ], and 0.5 [95\% CI: (0.3-0.8), $\mathrm{P}<0.02]$, respectively.

\section{The degree of IBL decreases OS and RFS}

Patients were divided into two groups according to the degree of blood loss (Group A: $\leq 250 \mathrm{~mL}$; Group B: $>250 \mathrm{~mL}$ ). We noted that the median RFS and OS decreased significantly with the increase of blood loss (Figure 3).

\section{The degree of IBL decreases RFS after $L H$}

A Kaplan-Meier analysis was performed to determine which clinicopathologic factors were associated with RFS after LH. Through univariate analysis, we found that tumor size and IBL (Figure 3) were significant predictors (Table 6), while our multivariate analysis determined that IBL was the only significant predictor of HCC recurrence (Table 6, $\mathrm{P}<0.05)$.

\section{Discussion}

This is the first article that confirms that IBL is an independent predictor of HCC patients who underwent LH long-term survival. Our data shows that the degree of IBL is related to a patient's OS and RFS after LH. In addition, tumor size and the number of tumors can also predict survival in HCC patients who underwent LH. However, advances in surgical techniques and anesthesia have made LH safer (21) and in some cases even better than $\mathrm{OH}$ (22-24), the amount of IBL related to LH is still a significant concern. Several clinicopathologic factors such as transfusion $(25,26)$, surgery approach $(27,28)$, and hepatic inflow occlusion (29) are of prognostic importance in patients with HCC after LH. Compared to $\mathrm{OH}$, only a few articles have reported how blood loss affects patients' shortterm outcomes during LH (8). However, Tranchart has recommended that $10-14 \mathrm{mmHg}$ pneumoperitoneum, low central venous pressure $\left(<5 \mathrm{cmH}_{2} \mathrm{O}\right)$, laparoscopy facilitated inflow and outflow control, and experienced laparoscopy surgical skills can effectively control bleeding (30). IBL has been noted as an independent prognostic factor for tumor recurrence and death (9), as well as for a worse survival rate for patients undergoing $\mathrm{LH}$ for colorectal cancer 
Table 3 Predictors of IBL in LH

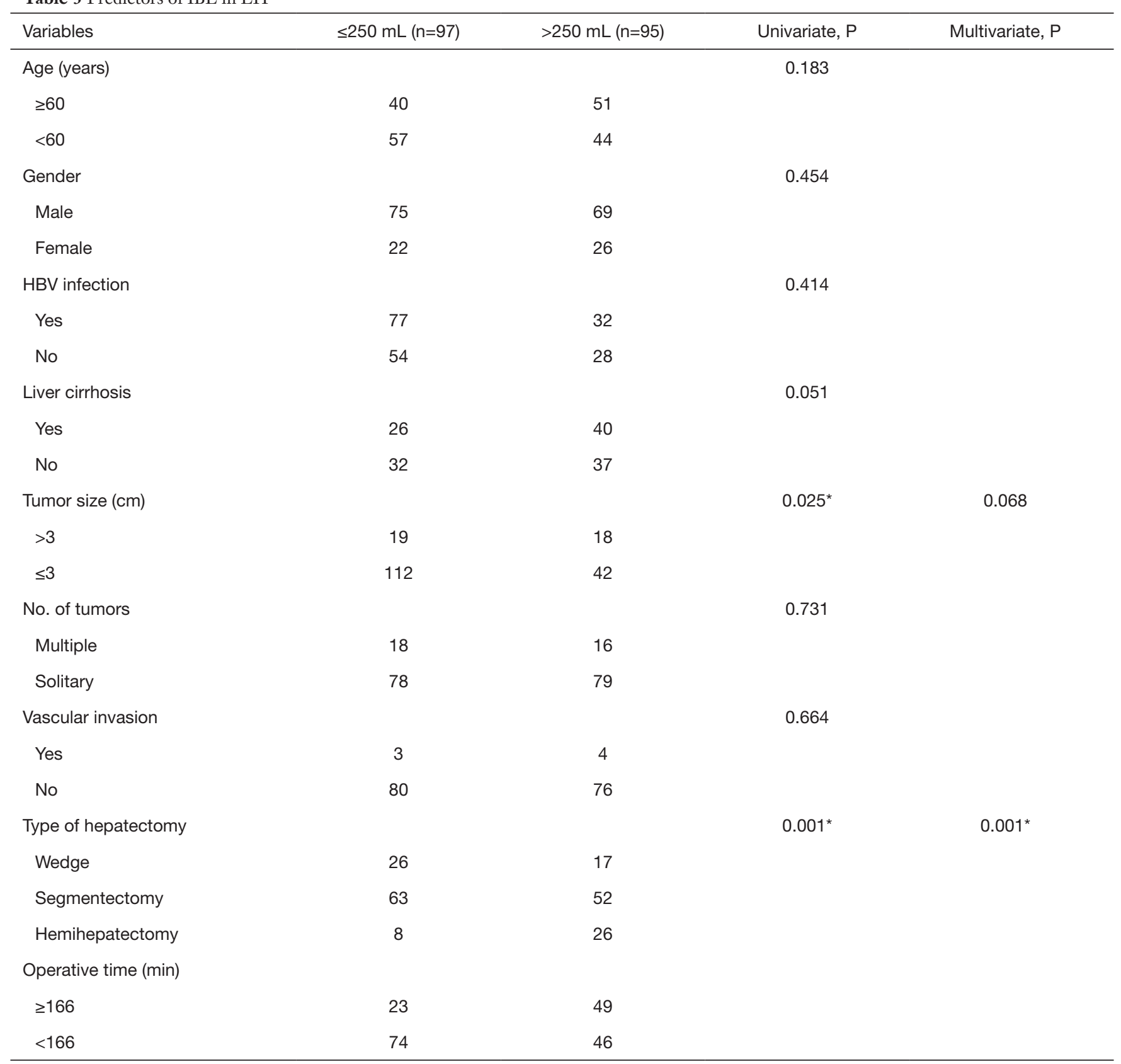

${ }^{*}, \mathrm{P}<0.05$ is statistically significant. IBL, intraoperative blood loss; $\mathrm{LH}$, laparoscopic hepatectomy; HBV, hepatitis B virus.

liver metastases (18). In our study, only a small number of patients had advanced cirrhosis (12\%), which may be the reason why cirrhosis was not a significant predictor of blood loss. LH's effect on patients with HCC and Child-Pugh class B liver disease should be further evaluated in future studies. Through our multivariate analysis, we determined that tumor size, operative time, and the type of hepatectomy were associated with blood loss (Table 3). The relationship between tumor size and bleeding has been reported previously. In $22 \%$ of the study's 192 patients, the tumor was larger than $5 \mathrm{~cm}$ in diameter and required a longer operative time, resulting in higher blood loss (31). The type of hepatectomy (hemihepatectomy) was also closely related to blood loss and operative time, with a prolonged operative 

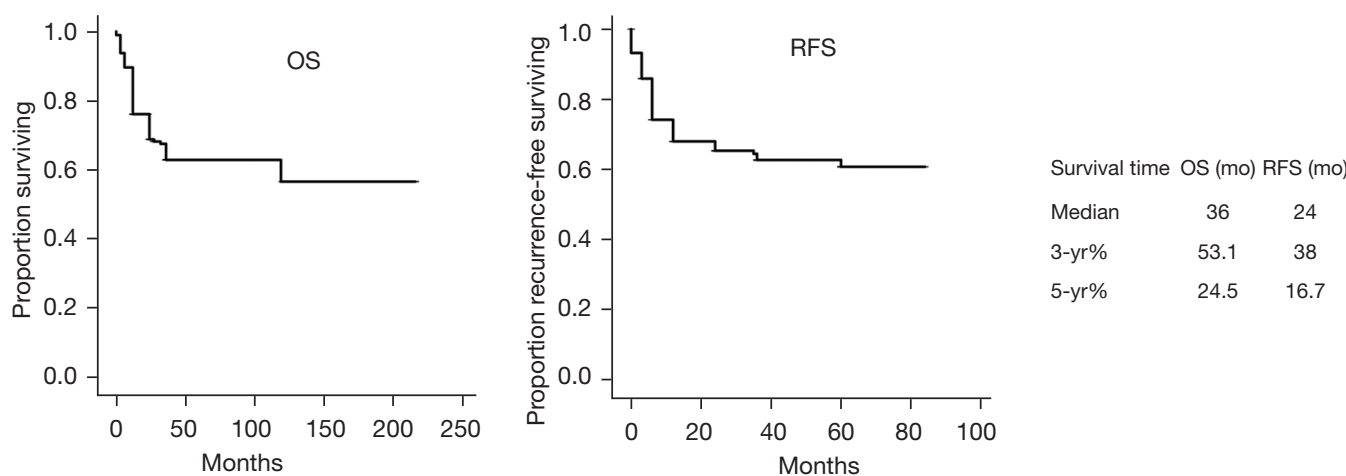

Figure 1 Kaplan-Meier estimates of survival and recurrence for the entire group of patients (n=192). OS, overall survival; RFS, recurrencefree survival.
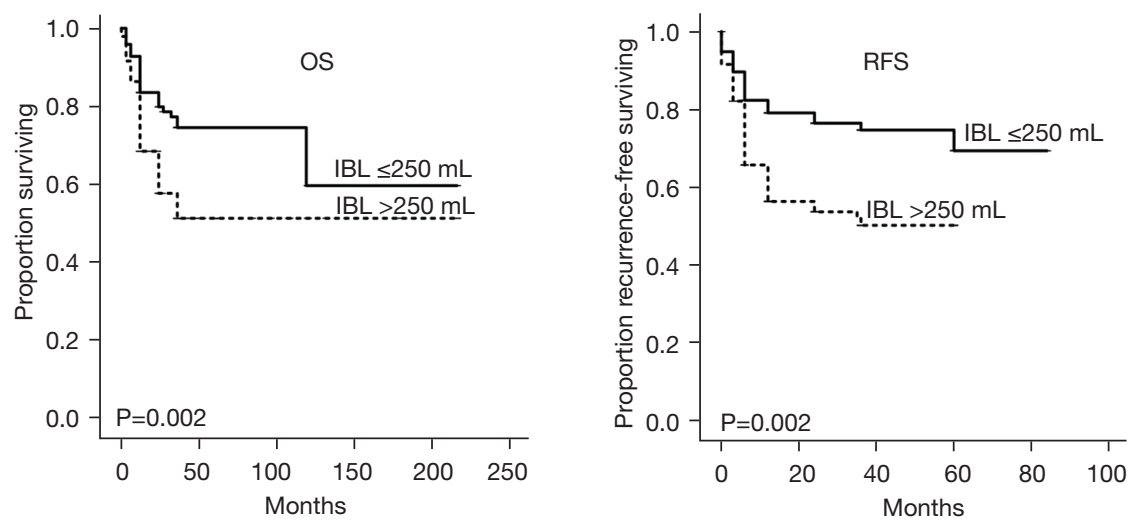

Figure 2 Kaplan-Meier estimates of OS and RFS for patients by IBL. OS, overall survival; RFS, recurrence-free survival; IBL, intraoperative blood loss.

time meaning an increase in blood loss. Thus, operative time and type of hepatectomy were dependent risk factors for increased IBL. This makes it easier to understand that the more complicated the resection, the longer the operative time. Therefore, the impact of hemihepatectomy on the long-term outcome of patients was significantly lower than other factors (Figure 3).

Through the univariate analysis, IBL and tumor size were the independent predictors of RFS in LH (Table 6, Figure 4), whereas multivariate analysis found IBL was the only independent predictor of RFS (Table 6). Our data demonstrated that $\mathrm{LH}$ was a predictor of a higher IBL and worse oncologic outcome. At the same time, we also observed that several patients with HCC recurrence undergoing secondary surgery, transcatheter arterial chemoembolization, oral chemotherapy, microwave radiofrequency ablation, and other methods had a significantly prolonged survival time. This also explains why the degree of blood loss affected the RFS time more significantly than the OS time of the patients.

The degree of IBL was also found to predict the OS and RFS. Patients were divided into two groups according to the degree of blood loss (Group A: $\leq 250 \mathrm{~mL}$; Group B: $>250 \mathrm{~mL}$ ), with the median RFS and OS decreasing significantly with an increased IBL. This further clarified the significant effect bleeding has on the OS and RFS time. In a high-quality publication by Katz (9), he found that IBL independently predicted OS and RFS after LH. He pointed out that more blood loss results in a longer operative time, organ hypoperfusion, and oxygen deficiency. Researchers on other types of cancer (32) have also illustrated the independent effect of bleeding on HCC recurrence, with the leading cause being anti-tumor immunosuppression.

Many reports have also suggested that a blood transfusion 
Table 4 Predictors of OS in LH

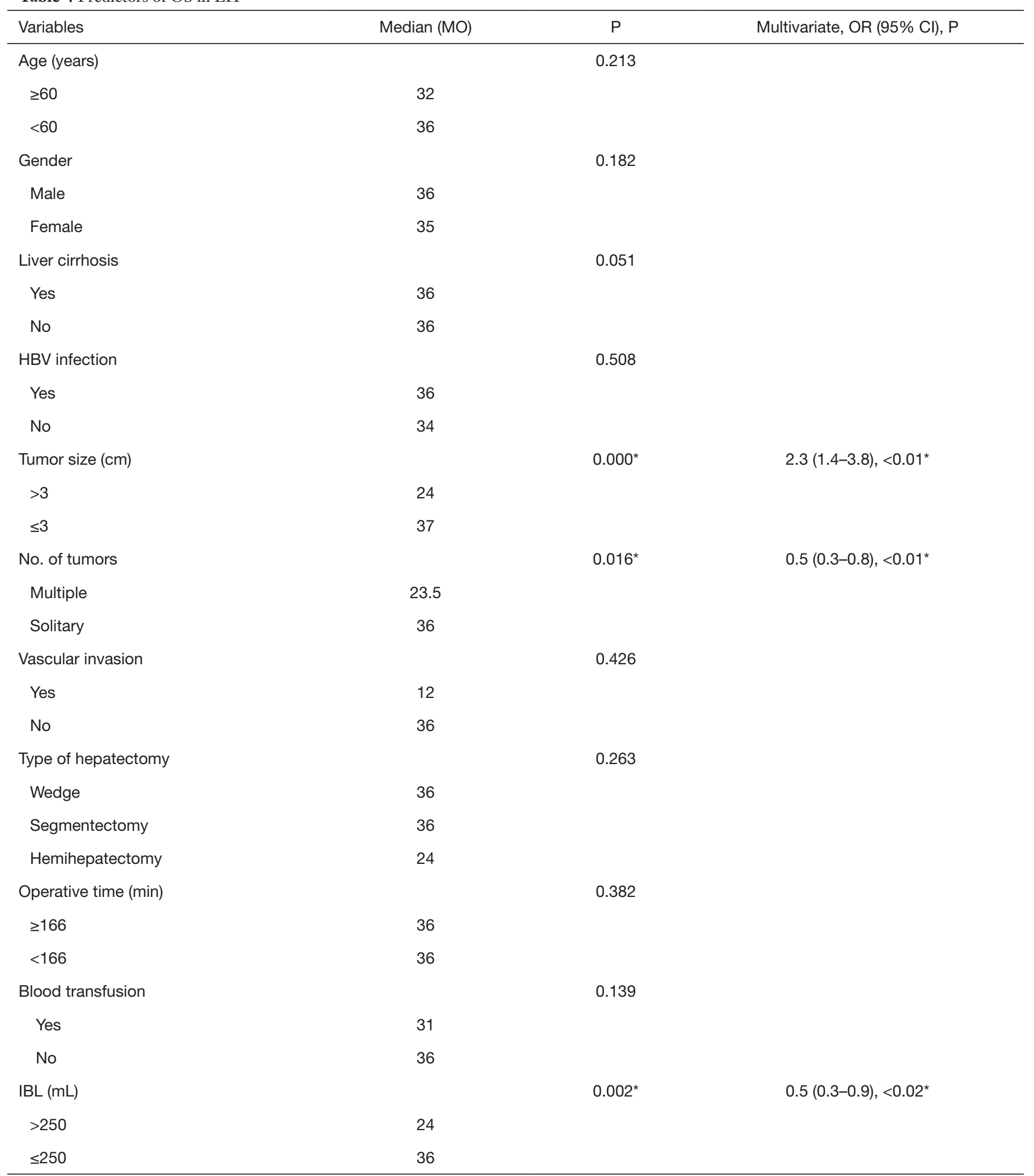

*, $\mathrm{P}<0.05$ is statistically significant. OS, overall survival; $\mathrm{LH}$, laparoscopic hepatectomy; MO, month; OR, odds ratio; Cl, confidence interval; HBV, hepatitis B virus; IBL, intraoperative blood loss. 
Table 5 Predictors of RFS in LH

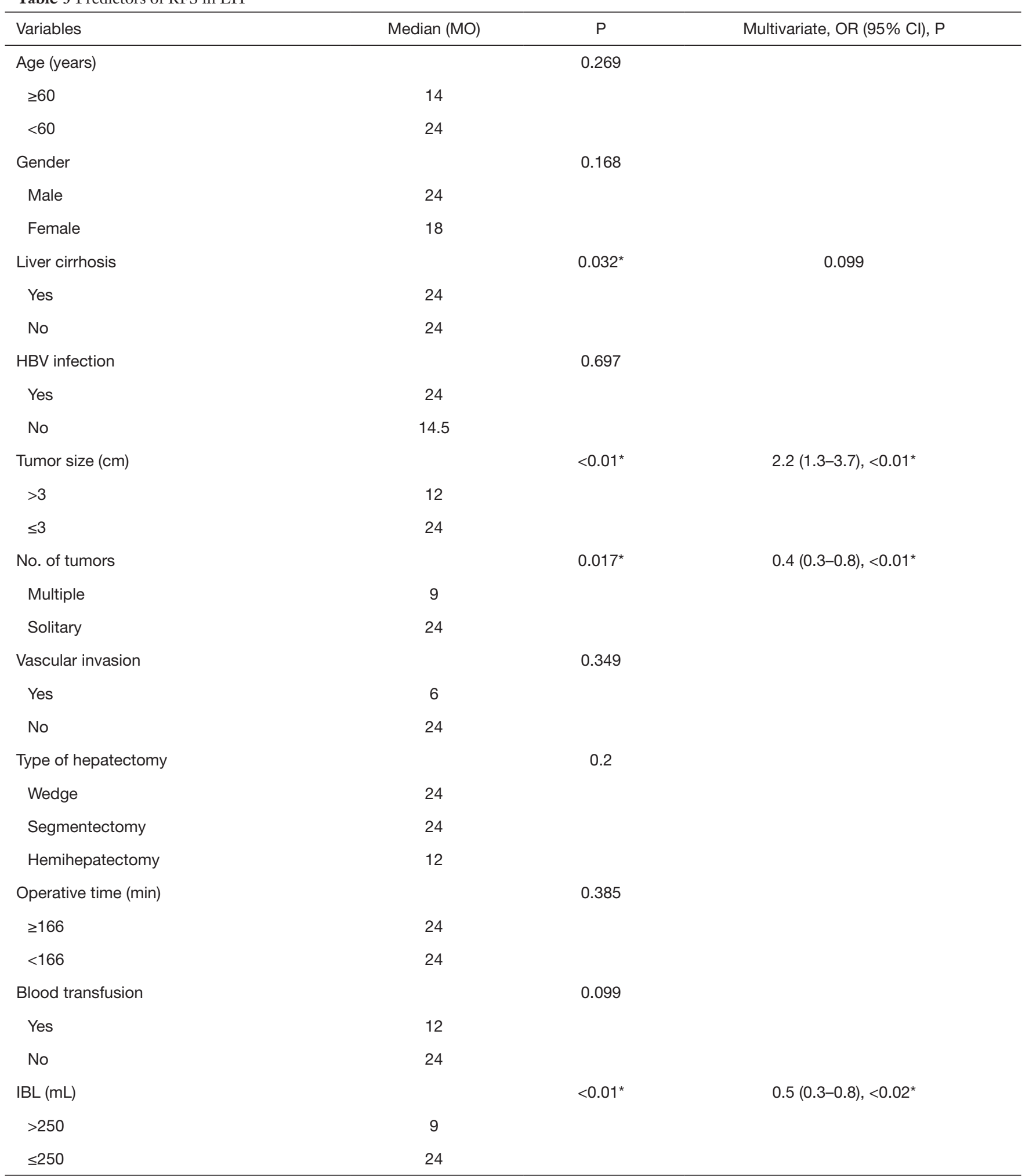

*, $\mathrm{P}<0.05$ is statistically significant. RFS, recurrence-free survival; LH, laparoscopic hepatectomy; MO, month; OR, odds ratio; Cl, confidence interval; HBV, hepatitis B virus; IBL, intraoperative blood loss. 

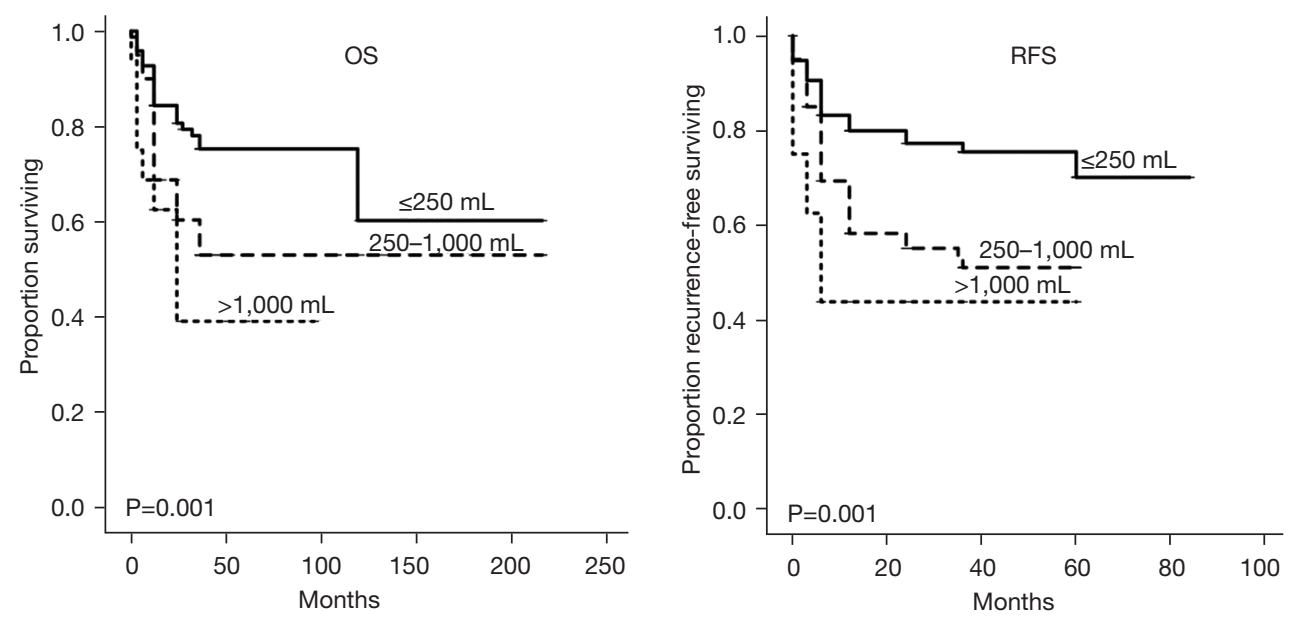

Figure 3 Dose-response relationships of IBL and OS, RFS. IBL, intraoperative blood loss; OS, overall survival; RFS, recurrence-free survival.

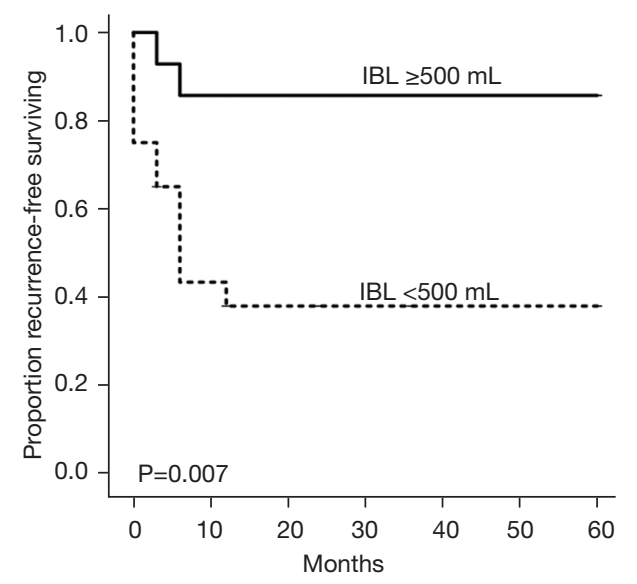

Figure 4 Kaplan-Meier estimates of RFS for laparoscopic major hepatectomy. RFS, recurrence-free survival; IBL, intraoperative blood loss.

while undergoing $\mathrm{OH}$ is a significant predictor of patient outcomes $(12,27,28,33)$. However, in our study, transfusion did not obtain a statistical significance for OS and RFS. The low transfusion rate (22\%) in our study may account for this. Compared to OH, $\mathrm{LH}$ results in less blood loss and can therefore reduce the need for blood transfusions.

Regarding the short-term outcomes of the patients analyzed, there were no significant differences determined. Only 41 of the 192 patients had complications after LH. Several studies (22-24) have also proved that LH is better than $\mathrm{OH}$ in terms of short-term outcomes, and these findings are consistent with our results. The type of hepatectomy is also an important factor that influences the degree of bleeding. In our study, wedge and segmental resection were implemented in $65 \%$ of the cases, while hemihepatectomy was only used for $35 \%$. This may explain why there were fewer postoperative complications and why the complication rate was low in our study. In our next study, we will continue to explore the relationship between LH and the short- and long-term outcomes of HCC patients.

Our report also confirms that in experienced hands, LH is safe and effective, leading to less blood loss and shorter hospital stays. Diversified methods improve the survival time of HCC patients after LH and improve their quality of life.

It is also important to note that our study had certain limitations. These included the follow-up time not being long enough and for which, in future studies, we will strive to increase to a period of more than 10 years. The sample size of the study could have also been expanded. However, as the center involved in the study specializes in LH, there will be more and more cases to study in the future and more advanced technologies involved. Overall, this will result in less bleeding, shorter hospital stays, and higher survival rates for HCC patients undergoing LH.

\section{Conclusions}

To conclude, we found that the degree of IBL is an independent predictor of the OS and RFS of HCC patients after LH. Therefore, it is paramount that various methods and surgical instruments be used to reduce IBL during LH. 
Table 6 Predictors of RFS in LH

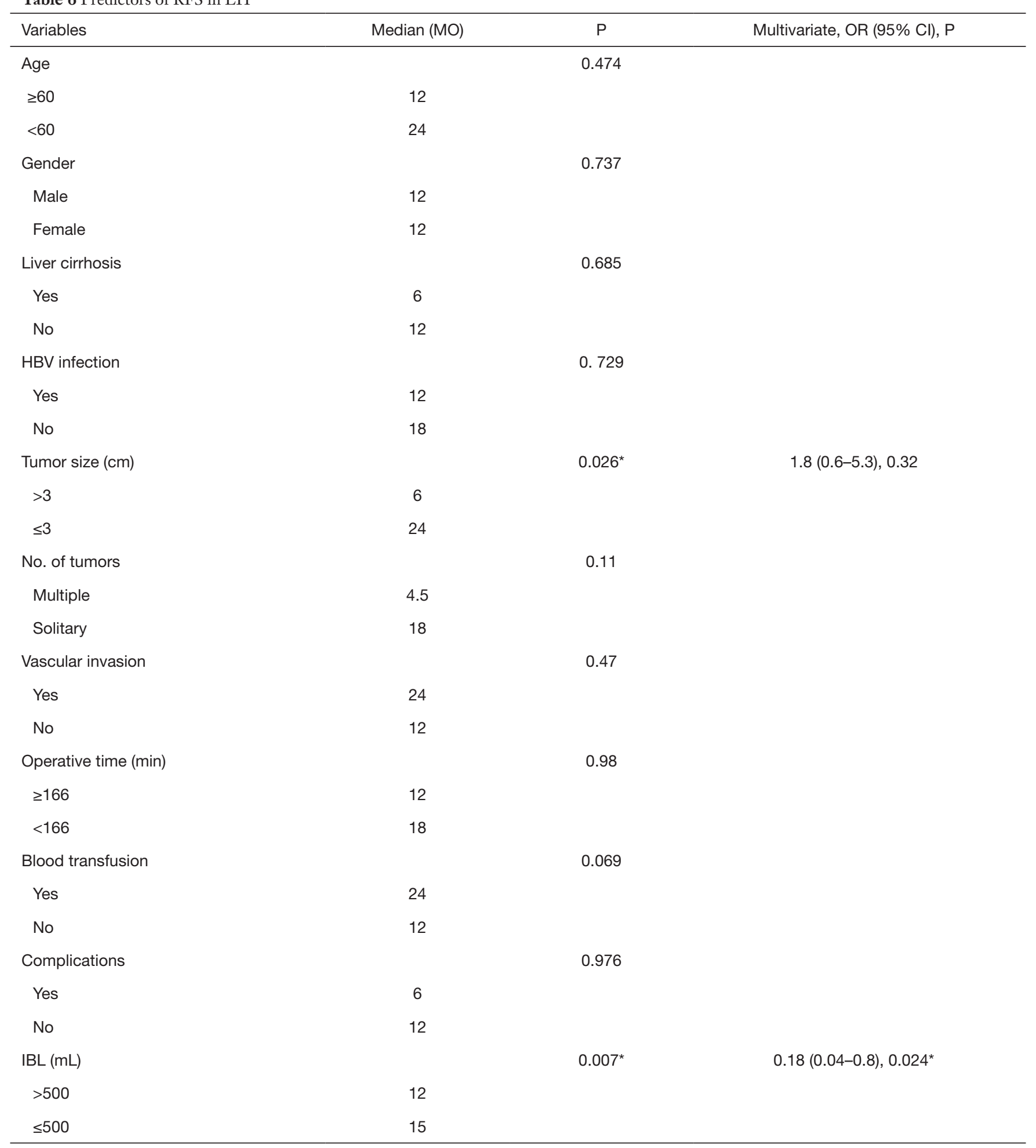

*, $\mathrm{P}<0.05$ is statistically significant. RFS, recurrence-free survival; $\mathrm{LH}$, laparoscopic hepatectomy; MO, month; OR, odds ratio; Cl, confidence interval; HBV, hepatitis B virus; IBL, intraoperative blood loss. 


\section{Acknowledgments}

Funding: None.

\section{Footnote}

Reporting Checklist: The authors have completed the STROBE reporting checklist. Available at https://dx.doi. org/10.21037/tcr-21-463

Data Sharing Statement: Available at https://dx.doi. org/10.21037/tcr-21-463

Conflicts of Interest: All authors have completed the ICMJE uniform disclosure form (available at https://dx.doi. org/10.21037/tcr-21-463). The authors have no conflicts of interest to declare.

Ethical Statement: The authors are accountable for all aspects of the work in ensuring that questions related to the accuracy or integrity of any part of the work are appropriately investigated and resolved. The study was conducted in accordance with the Declaration of Helsinki (as revised in 2013). The study was approved by Institutional Ethics Board of Sir Run Run Shaw Hospital of Zhejiang University (No. 20190821-6) and individual consent for this retrospective analysis was waived.

Open Access Statement: This is an Open Access article distributed in accordance with the Creative Commons Attribution-NonCommercial-NoDerivs 4.0 International License (CC BY-NC-ND 4.0), which permits the noncommercial replication and distribution of the article with the strict proviso that no changes or edits are made and the original work is properly cited (including links to both the formal publication through the relevant DOI and the license). See: https://creativecommons.org/licenses/by-nc-nd/4.0/.

\section{References}

1. Torre LA, Bray F, Siegel RL, et al. Global cancer statistics, 2012. CA Cancer J Clin 2015;65:87-108.

2. Wang FS, Fan JG, Zhang Z, et al. The global burden of liver disease: the major impact of China. Hepatology 2014;60:2099-108.

3. Elshamy M, Takahashi H, Akyuz M, et al. Evolution of a laparoscopic liver resection program: an analysis of 203 cases. Surg Endosc 2017;31:4150-5.
4. Buell JF, Cherqui D, Geller DA, et al. The international position on laparoscopic liver surgery: The Louisville Statement, 2008. Ann Surg 2009;250:825-30.

5. Aramaki O, Takayama T, Higaki T, et al. Decreased blood loss reduces postoperative complications in resection for hepatocellular carcinoma. J Hepatobiliary Pancreat Sci 2014;21:585-91.

6. Benzoni E, Cojutti A, Lorenzin D, et al. Liver resective surgery: a multivariate analysis of postoperative outcome and complication. Langenbecks Arch Surg 2007;392:45-54.

7. Kamiyama T, Nakanishi K, Yokoo H, et al. Perioperative management of hepatic resection toward zero mortality and morbidity: analysis of 793 consecutive cases in a single institution. J Am Coll Surg 2010;211:443-9.

8. Gupta R, Fuks D, Bourdeaux C, et al. Impact of intraoperative blood loss on the short-term outcomes of laparoscopic liver resection. Surg Endosc 2017;31:4451-7.

9. Katz SC, Shia J, Liau KH, et al. Operative blood loss independently predicts recurrence and survival after resection of hepatocellular carcinoma. Ann Surg 2009;249:617-23.

10. Finch RJ, Malik HZ, Hamady ZZ, et al. Effect of type of resection on outcome of hepatic resection for colorectal metastases. Br J Surg 2007;94:1242-8.

11. Yeh CN, Chen MF, Lee WC, et al. Prognostic factors of hepatic resection for hepatocellular carcinoma with cirrhosis: univariate and multivariate analysis. J Surg Oncol 2002;81:195-202.

12. Harada N, Shirabe K, Maeda T, et al. Blood transfusion is associated with recurrence of hepatocellular carcinoma after hepatectomy in Child-Pugh class A patients. World J Surg 2015;39:1044-51.

13. Jin B, Chen MT, Fei Y'T, et al. Safety and efficacy for laparoscopic versus open hepatectomy: A meta-analysis. Surg Oncol 2018;27:A26-34.

14. Rao A, Rao G, Ahmed I. Laparoscopic vs. open liver resection for malignant liver disease. A systematic review. Surgeon 2012;10:194-201.

15. Kobayashi S, Fukui K, Takeda Y, et al. Short-term outcomes of open liver resection and laparoscopic liver resection: Secondary analysis of data from a multicenter prospective study (CSGO-HBP-004). Ann Gastroenterol Surg 2018;2:87-94.

16. Miguchi M, Yoshimitsu M, Hakoda K, et al. Short-term outcomes of laparoscopic surgery in octogenarians with colorectal cancer: a single-institution analysis. Surg Today 2018;48:292-9.

17. Liu SP, Cheng XW, Tian X, et al. Laparoscopic surgery 
for endometrial cancer in aged patients: Experience from a tertiary referral center in Eastern China. J Cancer Res Ther 2017;13:761-6.

18. Margonis GA, Kim Y, Samaha M, et al. Blood loss and outcomes after resection of colorectal liver metastases. J Surg Res 2016;202:473-80.

19. Jiang $\mathrm{W}$, Fang YJ, Wu XJ, et al. Intraoperative blood loss independently predicts survival and recurrence after resection of colorectal cancer liver metastasis. PLoS One 2013;8:e76125.

20. Dindo D, Demartines N, Clavien PA. Classification of surgical complications: a new proposal with evaluation in a cohort of 6336 patients and results of a survey. Ann Surg 2004;240:205-13.

21. Lai EC, Tang CN, Ha JP, et al. Laparoscopic liver resection for hepatocellular carcinoma: ten-year experience in a single center. Arch Surg 2009;144:143-7; discussion 148.

22. Luo L, Zou H, Yao Y, et al. Laparoscopic versus open hepatectomy for hepatocellular carcinoma: short- and long-term outcomes comparison. Int J Clin Exp Med 2015;8:18772-8.

23. Mirnezami R, Mirnezami AH, Chandrakumaran K, et al. Short- and long-term outcomes after laparoscopic and open hepatic resection: systematic review and metaanalysis. HPB (Oxford) 2011;13:295-308.

24. Tsai KY, Chen HA, Wang WY, et al. Long-term and short-term surgical outcomes of laparoscopic versus open liver resection for hepatocellular carcinoma: might laparoscopic approach be better in early HCC? Surg Endosc 2019;33:1131-9.

25. Nassar A, Hobeika C, Lamer C, et al. Relevance of blood loss as key indicator of the quality of surgical care in

Cite this article as: $\mathrm{Lv}$ X, Zhang L, Yu H, Yu X. Laparoscopic hepatectomy for hepatocellular carcinoma: short- and longterm outcomes with blood loss. Transl Cancer Res 2021;10(10): 4303-4315. doi: 10.21037/tcr-21-463 laparoscopic liver resection for colorectal liver metastases. Surgery 2020;168:411-8.

26. Asahara T, Katayama K, Itamoto T, et al. Perioperative blood transfusion as a prognostic indicator in patients with hepatocellular carcinoma. World J Surg 1999;23:676-80.

27. Li W, Zhou X, Huang Z, et al. Short-term and longterm outcomes of laparoscopic hepatectomy, microwave ablation, and open hepatectomy for small hepatocellular carcinoma: a 5-year experience in a single center. Hepatol Res 2017;47:650-7.

28. Machado MA, Surjan RC, Basseres T, et al. The laparoscopic Glissonian approach is safe and efficient when compared with standard laparoscopic liver resection: Results of an observational study over 7 years. Surgery 2016;160:643-51.

29. Herman P, Perini MV, Coelho F, et al. Half-Pringle maneuver: a useful tool in laparoscopic liver resection. J Laparoendosc Adv Surg Tech A 2010;20:35-7.

30. Tranchart H, O'Rourke N, Van Dam R, et al. Bleeding control during laparoscopic liver resection: a review of literature. J Hepatobiliary Pancreat Sci 2015;22:371-8.

31. Levi Sandri GB, Spoletini G, Vennarecci G, et al. Laparoscopic liver resection for large HCC: short- and long-term outcomes in relation to tumor size. Surg Endosc 2018;32:4772-9.

32. Nakanishi K, Kanda M, Kodera Y. Long-lasting discussion: Adverse effects of intraoperative blood loss and allogeneic transfusion on prognosis of patients with gastric cancer. World J Gastroenterol 2019;25:2743-51.

33. Makino Y, Yamanoi A, Kimoto T, et al. The influence of perioperative blood transfusion on intrahepatic recurrence after curative resection of hepatocellular carcinoma. Am J Gastroenterol 2000;95:1294-300. 